\title{
A política externa de Reagan e a redemocratização da América Latina (1981-1988)
}

\author{
Marcos Paulo Tonial ${ }^{*}$
}

\begin{abstract}
Resumo: No momento da transição de regimes autoritários para regimes democráticos, muitos são os elementos, atores e interesses nesse processo. Regimes políticos e ideologias tão distintos na América Latina, estabelecidos em momentos diferentes, porém interligados num mesmo processo (regime de Segurança Nacional nas ditaduras e democracia posteriormente), não surgiram apenas de relações internas e interesses de grupos locais, mas também foram fomentados por ações internacionais, cujas implicações são o tema deste texto.

Em geral, temos a impressão de que a política de Ronald Reagan para a América Latina, nos anos 1980, foi truculenta; porém, este artigo propõe-se a observar e analisar as atividades diplomáticas de Reagan e seus assessores com o objetivo de verificar a influência dessa política sobre a América Latina.
\end{abstract}

\footnotetext{
* Mestre em História pela Universidade Federal do Rio Grande do Sul. Professor do Ensino Médio nos colégios Sociedade Educacional Afrânio, Colégio Coração de Maria e Escola Estadual Cândido José de Godói. Professor do Ensino Fundamental (EJA) na Escola Estadual Imperatriz Leopoldina.
}

Anos 90, Porto Alegre, v. 13, n. 23/24, p.241-253, jan./dez. 2006 


\section{A política externa de Reagan e a redemocratização...}

O interesse do texto é elaborar um mapeamento das razões que levaram o governo norte-americano a conduzir uma política externa com intuito de destituir governos ditatoriais, fomentando a necessidade de abertura democrática na América Latina, região entendida, na época, como área estratégica para os Estados Unidos.

Palavras-chave: Ronald Reagan - América Latina - abertura democrática.

No início dos anos 1980, boa parte dos países da América Latina vivenciou um importante processo histórico: a transição de regimes autoritários para democracias. As características e as implicações dos diferentes agentes históricos no período deixaram como legado a tentativa de estruturação de um regime político que se propunha ser a solução para o fracasso econômico e político dos militares nos anos anteriores. A democracia surgiria como um regime político ainda frágil, a ser reconstruído e organizado, mas imbuído de esperança na tentativa de recuperação e desenvolvimento da região.

$\mathrm{Na}$ percepção da importância de diferentes agentes históricos nesse processo, faz-se necessário detectar a presença de fatores externos na construção do ambiente democrático para a América Latina, principalmente notar a existência de uma agenda norte-americana para esse fim.

É preciso perceber que uma das características da política externa dos Estados Unidos, no decorrer dos anos 1980, período sob a administração do republicano Ronald Reagan, foi o estabelecimento dos chamados conflitos de baixa intensidade, os quais se caracterizavam pela intervenção militar direta e/ou indireta dos Estados Unidos em países cujas políticas poderiam prejudicar os interesses estratégicos norte-americanos. Porém, houve por parte de Washington, nesse mesmo período, a construção de uma política diplomática com o objetivo de apoiar as transições democráticas na América Latina. Ou seja, por mais que a política externa de Reagan tenha sido truculenta, havia uma agenda bem clara por parte da Casa Branca sobre a necessidade de estabelecer uma 
diplomacia alinhada com a América Latina, vista então como área estratégica e de segurança para os Estados Unidos.

A América Latina foi então inserida na formulação da política externa dos Estados Unidos, cuja referência estava na concorrência internacional com a Europa Ocidental e Japão e na administração da economia doméstica norte-americana. As questões econômicas da América Latina deveriam ser resolvidas nas esferas da economia internacional, mediante uma relação direta e bilateral com os Estados Unidos. Assim, a política norte-americana de incentivo à abertura democrática se faz num momento de rearticulação de sua política internacional. Dentro desse contexto, o discurso em defesa da democracia aparece como carro-chefe dentro das negociações dos Estados Unidos com a América Latina.

Num primeiro momento, deve-se levar em conta que a estratégia norte-americana trata-se de um recurso estabelecido por uma grande potência com o objetivo de manter a hegemonia sobre sua área geográfica de controle. Hegemonia e grande potência foram dois conceitos desenvolvidos por Antonio Gramsci no sentido de compreensão da capacidade de determinados Estados em influenciar a atividade política e econômica de outros. A nação hegemônica é a nação controladora e os fatores definidores da condição de grande potência, quais sejam, extensão territorial, força econômica, força militar e paz interna, conferem tamanha estabilidade à grande potência que lhe permite traçar, em caráter permanente, sua linha de atuação e nortear a ação dos demais Estados (Gramsci, 1978, p. 191-192). Portanto, a posição da grande potência sobre a atuação política e econômica de outros Estados influencia suas atividades de tal forma que estes não podem ser desconsiderados pela historiografia. A influência da grande potência Estados Unidos foi de suma importância no processo de transição da ditadura à democracia na América Latina a partir dos anos 1980. A política norte-americana de incentivo à abertura 
A política externa de Reagan e a redemocratização...

democrática para a América Latina se faz num momento de rearticulação de sua política internacional, buscando fortalecer sua influência de potência-guia ao mesmo tempo em que visa evitar a passagem ou aproximação dos estados satélites ao bloco oposto, diga-se soviético.

Dessa forma, a partir da década de 1980, no plano políticoideológico, os EUA desenvolveram internamente a construção de uma política democrática-liberal após a derrota do welfare state, assim como buscaram estender essa política a uma série de países da América Latina administrados por governos ditatoriais ou em fase de transição dos regimes militares. A democracia, sob o ponto de vista norte-americano, deveria ser estabelecida na América Latina como um regime político cujo objetivo é a adoção ou manutenção de estruturas políticas e econômico-sociais homogêneas vantajosas quanto às necessidades do sistema político e econômico-social da potência hegemônica. A idéia de democracia liberal está ligada ao desenvolvimento de uma política econômica liberal. O contexto econômico mundial do início dos anos $1980 \mathrm{fez}$ com que, ao mesmo tempo em que os modelos políticos ditatoriais iam perdendo seu fôlego, fossem desenvolvidas justificativas acerca de uma nova democracia. Essa democracia liberal principia na América Latina sob uma forma muito contraditória: apesar dos lentos avanços políticos conquistados pelos diversos setores da sociedade, não foi acompanhada por uma melhoria nas condições de vida das grandes maiorias nacionais, por isso foi compreendida, desenvolvida e divulgada à esfera político-institucional, sem engajamento social, sem melhoria das condições sociais da população.

É fato que os Estados Unidos não tiveram um papel central na transição para a democracia na América Latina. Cada país latino-americano, que nos anos 1980 iniciou o processo de redemocratização, seguiu regras próprias de transição em razão de suas particularidades, interesses e atividades de diferentes atores 
históricos locais. Porém, é necessário notar que os Estados Unidos criaram uma política externa para a América Latina cuja principal característica esteve em incentivar esses processos de redemocratização e perceber as razões que os levaram a tomar essa postura.

A crise dos governos militares parece ter sido aproveitada pelo governo Reagan para a formulação de um novo consenso sobre a democracia que deveria ser estabelecida. A democracia liberal servia aos interesses norte-americanos nos anos 1980. Assim, os Estados Unidos aproveitaram-se do momento histórico para estabelecer uma nova diplomacia na América Latina pautada pela nova onda democrática. O incentivo à democracia fazia-se num período já de transição, pois sob o ponto de vista de Washington seria melhor ter ao lado aliados democráticos, porém com governos pró-Estados Unidos, do que administradores militares voltados para um forte nacionalismo.

Nos discursos de Reagan a democracia aparece como necessária e facilitadora do estabelecimento da economia de mercado. Para Washington, as ditaduras atravancavam, em geral, a economia de mercado em razão do forte nacionalismo, daí uma das razões da necessidade de transição para a democracia.

Acredito que assim, a nova democracia (diga-se liberal) surgia como um projeto para ocultar a dominação de classe em escala nacional e internacional, fazendo crer aos membros de uma determinada nação a idéia da existência imaginada de coesão social em nome da unidade em detrimento da transformação social, bem como a idéia de participação (ilusória) nas decisões (através das eleições).

Sobre a transição, deve-se perceber que não só a política externa norte-americana sentiu a necessidade da saída dos militares, assim como amplos setores dos países afetados pela ditadura buscaram na abertura democrática a possibilidade de manutenção do status quo. Conforme O’Donnell, o que pode ser observado foi que 


\section{A política externa de Reagan e a redemocratização...}

a visão de industriais, comerciantes, banqueiros e proprietários rurais, reclamando da política governamental e mesmo, ocasionalmente, expressando uma preferência por eleições abertas, teve o duplo efeito de constituir-se em uma dissensão que não pôde ser reprimida e que o regime não gozava do amplo consenso que alegava ter (O’Donnell, 1988, p. 86). Sendo assim, os militares começaram a ficar sozinhos, sem os seus apoiadores habituais.

Devemos lembrar que a legitimidade por parte dos militares em impor a ditadura teve como base a ideologia da Segurança Nacional. Não obstante os fatores intrínsecos e fundamentais dessa política na América Latina, as justificativas para o fato do rigor militar do governo estiveram ligadas diretamente ao nacionalismo. A tradição e a glorificação do passado de luta do exército fizeram com que os valores nacionais fossem fortalecidos e estabelecidos de forma contundente. A valorização dos símbolos da nação, e o exército não deixou de ser um, teve papel importante no sentido de levar a idéia de que a defesa da soberania era questão primordial. Mas não só isso: os militares (em seu discurso) objetivavam também novas nações, uma nova política, livre da corrupção e buscando o fim das desigualdades sociais (Comblin, 1980, p. 183). Os militares elaboram esse discurso com objetivo específico: deter a possibilidade do avanço socialista.

Mas é necessário perceber que as implicações dessa ideologia determinaram um caráter essencial e objetivo da entrada dos poderes militares em ação: os setores que insistiam para essa radicalização eram os mesmos que, desgastados após a tentativa populista, buscaram novas formas de manter sua hegemonia. As elites locais, aliadas aos interesses geopolíticos estadunidenses, visualizaram na ditadura militar a forma possível para assegurar o seu poderio econômico, porém era necessário justificar essas ações perante toda a comunidade. O discurso da Segurança Nacional cumpriu esse papel no sentido de alertar sobre o perigo comunista e manter os valores cristãos (basicamente católicos) e os direitos 
de propriedade, bem como alijar a esquerda da possibilidade de qualquer apoio popular (tentando-se evitar, por exemplo, a influência da Revolução Cubana).

O ideal de nova nação dos militares não se concretizou, pois o caráter de capitalismo dependente e a insuficiência de um desenvolvimento econômico autônomo demonstraram a real situação das economias dos países latino-americanos.

Os regimes militares estabelecidos na América Latina postergaram as aspirações populares em nome da Segurança Nacional e do combate à subversão. E justificaram sua política econômica antipopular em nome da necessidade de crescer primeiro para distribuir depois os frutos desse crescimento.

A política econômica dos governos militares caracterizou-se pelo favorecimento à concentração e à centralização econômica que levou ao mais alto nível a concentração de renda nas mãos de uma minoria da população, fazendo agravar-se ainda mais as desigualdades sociais e o caráter de região subdesenvolvida. ${ }^{1}$ Em conseqüência dessa política, marginalizaram-se também as amplas camadas da população submetidas ao desemprego e ao subemprego, o que levou a América Latina a ostentar altos índices de pobreza.

Mas é interessante notar que nesse processo não somente alienaram-se importantes riquezas naturais como se entregou o controle da economia ao capital internacional, orientando o desenvolvimento interno de acordo com seus interesses e agravando a tal ponto as dificuldades cambiais que os países da América Latina converteram-se nos maiores devedores do mundo.

Além disso, a idéia da Segurança Nacional fez com que fosse extinta a participação dos trabalhadores na direção de questões importantes, como a da Previdência Social, assim como reprimidos os sindicatos, os partidos trabalhistas e as centrais sindicais; efetuou-se um severo controle sobre a imprensa, bem como 


\section{A política externa de Reagan e a redemocratização...}

qualquer ato que demonstrasse claramente uma tendência contrária às atitudes dos militares.

Após terem cumprido o seu papel, os militares saírem de cena foi uma questão de tempo, objetivando-se uma transição para um regime democrático. A influência norte-americana teve um papel importante, desenvolvendo e divulgando idéias democráticas, construindo um novo conceito de democracia.

Aquilo que se convencionou chamar de redemocratização, no início dos anos 1980, trouxe uma série de questionamentos por amplos segmentos da sociedade civil acerca das regras e da conduta política a partir de então. A herança militar (a repressão, o controle, bem como o fracasso na condução da economia) fez com que o processo de redemocratização fosse levado por etapas, onde num primeiro momento haveria de ser garantido o voto popular e estabelecidas as regras eleitorais, partindo-se para a reorganização controlada dos órgãos de representação até, por fim, o estabelecimento de nova constituição com garantias plenas de liberdade de expressão.

O enfrentamento aos governos autoritários para a volta da democracia na América Latina foi uma batalha travada por uma ampla maioria de membros da esquerda formada por socialistas, comunistas e outros, os quais doaram boa parte de suas vidas pelo direito de expressar suas idéias, de deixar claro a sua vontade e a sua luta por democracia. Porém, o seu empenho foi basicamente contra os militares, e estes foram apenas uma parte do poder que instituiu os governos ditatoriais.

As elites econômicas nacionais, em sua maioria apoiadas pelo governo norte-americano, mantiveram o apoio aos militares enquanto estes pudessem conduzir politicamente seus interesses. Após terem cumprido o seu papel, qual seja, repressão sobre os movimentos sindicais e operários e vínculo financeiro dependente através do endividamento externo (levado a patamares altíssimos), sair da administração do Estado, porém não perdendo seu poder 
político, foi a conseqüência imediata. É claro que a decadência dos regimes militares também esteve vinculada à imperícia destes na condução de sua política econômica ou pelo término de sua legitimidade perante a sociedade, porém isso também foi resultado de uma crise econômica advinda da recessão enfrentada pelo capitalismo mundial. Após o fim dos regimes ditatoriais, poucos foram os que lutaram pela democracia e chegaram ao poder através das eleições regulares. O poder político ficou com uma maioria de representantes das elites econômicas nacionais, os quais apoiaram a construção de um regime democrático que estivesse vinculado aos seus próprios interesses, onde não houvesse amplas reformas, mantendo-se o conservadorismo, efetuando-se uma democracia pelo alto, e no qual as populações dos Estados em processo de transição, por sua vez, teriam sua ação bastante limitada.

Os governos eleitos democraticamente não traduziram em atos as palavras de campanha eleitoral, e o que se começou a construir foi a democracia sem adjetivos, divulgada como forma de liberdade de expressão e cidadania, porém com nações miseráveis, endividadas, com uma gigantesca população à mercê da violência institucionalizada, com desigualdades sociais alarmantes e uma concentração de renda alcançando níveis inaceitáveis.

Portanto, a ideologia de segurança nacional e a democracia liberal, apesar de apresentarem-se em momentos diferentes, tornaram-se partes de um mesmo processo. Para Theotonio dos Santos:

“(...) diante da onda revolucionária, entre 1960 e 1970, a resposta foram regimes militares com estratégia de segurança nacional. Diante da vitória destes regimes e da emergência do nacionalismo militar, desde o começo da década de 70 foram fomentados regimes democráticos liberais e civis sob a liderança de forças conservadoras. O sucesso destes regimes, na década de 80, favoreceu políticas econômicas selvagens de livre-mercado, as quais arruinaram 


\section{A política externa de Reagan e a redemocratização...}

empresas nacionais e locais em favor das corporações multi e transnacionais e até globais." (Santos, 1996, p. 35).

A ideologia de segurança nacional e a democracia liberal tornaram-se projetos, conceitos e ação política de forças conservadoras que atenderam a determinados interesses, desenvolvidos como falsa consciência para ocultar dominação de classe, utilizados ou esquecidos de acordo com as circunstâncias. Assim, tanto a democracia liberal como o nacionalismo militar são utilizados ou abandonados para fins de interesses específicos. Confirma, assim, a impossibilidade do nacionalismo militar ter o mesmo caráter e a mesma importância, pois, de fato, a partir dos anos 1980 ele será um impedimento para a expansão do capital. Até nos parece curiosa e contraditória a política norte-americana sob domínio dos republicanos: internamente estabelece um pensamento neoconservador, nacionalista, antiigualitário e anticomunista, valores nacionais que buscavam manter o ideário da liberdade e do cristianismo, contra a ameaça comunista. Por sua vez, o discurso destinado às nações latino-americanas era justamente o contrário, ou seja, a valorização da nação tornava-se um impedimento ao crescimento, era necessário abrir-se à nova "onda globalizante". O que pode parecer contraditório torna-se plausível quando analisada a política internacional norte-americana dentro de um contexto de recuperação da crise dos anos 1970. Para os republicanos, o nacionalismo militar, agora nos anos 1980, tornava-se um impedimento para a expansão do capital, por isso a necessidade de redemocratização.

É preciso lembrar que no primeiro mandato de Ronald Reagan não houve agressão aos governos militares por parte dos Estados Unidos, nem a busca de reprimir as atividades dos ditadores, pois melhor estar com eles do que com a possibilidade de governos de esquerda. Por essa razão, nesse momento, a questão da democracia e dos direitos humanos não aparece com tanta ênfase. Com as 
transições, esses vocábulos começam a aparecer com mais freqüência, procurando enfatizar o "papel significativo" dos Estados Unidos nesse processo.

Autores latino-americanos demonstram que se os Estados Unidos incentivaram a democratização na América Latina nos anos 1980, ela deveria seguir um padrão que não afetasse os interesses estratégicos e econômicos da potência hegemônica. A idéia de construção de uma democracia latino-americana deveria estar vinculada à necessidade de abertura dos mercados e menor intervenção do governo na economia, deveria seguir os ideários liberais da era Reagan. Demonstra-se assim, a tentativa de construção de uma democracia com determinados limites, enfim, sem adjetivos.

Torna-se, portanto, possível estabelecer algumas razões que fizeram o Governo republicano de Ronald Reagan desenvolver uma agenda diplomática para apoiar os processos de redemocratização na América Latina: a) o novo enfrentamento dos Estados Unidos com a União Soviética, a partir do início dos anos 1980, estabeleceu uma estratégia norte-americana que não aceitava a passagem ou a aproximação das nações de sua área de influência ao bloco oposto, estabelecendo assim o caráter da América Latina como um setor de importância estratégica; o objetivo era controlar a ação dessa região no plano internacional, orientando as opções ideológicas e as "melhores" práticas políticas, as quais necessariamente deveriam ser vantajosas para a potência hegemônica; b) os Estados Unidos deveriam, para sua própria segurança, evitar o fortalecimento das esquerdas na região, sejam elas guerrilhas ou governos de orientação marxista já instituídos, como o cubano e o nicaragüense, assim como evitar a passagem de países ainda capitalistas para o bloco oposto; c) estabelecido o cenário internacional na transição dos anos 1970 para os anos 1980, a democracia apareceria nos discursos e nas propostas do Governo norte-americano como a saída para a crise econômica e política vivenciada pela América Latina, porém esse discurso 
A política externa de Reagan e a redemocratização...

dissimulava a intenção do estabelecimento de uma estratégia de segurança norte-americana, a qual via no regime democrático uma forma de deter a possibilidade do surgimento e/ou fortalecimento de regimes de esquerda, bem como possível desalinhamento de países da América Latina com a política internacional da nova administração norte-americana; d) a nova política econômica (liberal) dos Estados Unidos na era Reagan buscava a abertura dos mercados, menor intervenção do Estado na economia e livre circulação de capitais na América Latina; a maioria dos militares latino-americanos ainda possuía um forte caráter nacionalista, o qual impedia a implementação de tais políticas; a democratização surgiria nos discursos dos republicanos da Casa Branca num momento em que a América Latina era visualizada como região estratégica para a possibilidade de acumulação de capitais privados; e) o estabelecimento das novas regras de condução econômica para os países latino-americanos veio, principalmente, através da pressão norte-americana sobre os órgãos financeiros mundiais, como FMI, Bird e Bid, os quais liberavam financiamentos impondo determinadas condições, tais como abertura de mercados aos capitais externos, livre circulação de mercadorias e serviços e menor intervenção do Estado na economia.

Recebido em 26/05/2006.

Aprovado em 17/08/2006.

Reagan's external politics and re-democratization in Latin America (19811988)

Abstract: At the moment of the transition of authoritarian regimes to democratic regimes, several ones are the elements, actors, and interests in this process. Political regimes and ideologies so diverse in Latin America, established in different moments, but interlinked in a same process - Regime of National Safety during the dictatorships and democracy afterwards - did not just arise from internal relations and interests of local groups, but they were also fomented by international actions, whose implications are the subject of this text.

Anos 90, Porto Alegre, v. 13, n. 23/24, p.241-253, jan./dez. 2006 


\section{Marcos Paulo Tonial}

In general, we have impression that Ronald Reagan's politics was truculent to Latin America in the 80 's, but this article proposes to observe and analyze Reagan and his advisers' activities with the aim of verify the influence of this politics on Latin America.

The interest of the text is elaborate a charting about the reasons that North American government had, in order to conduct an external politics with the purpose of dismissing dictatorial government, fomenting the necessity of democratic opening in Latin America. That region was understood as a strategic area to United States of America then.

Keywords: Ronald Reagan - Latin America - democratic opening.

\section{Notas}

${ }^{1}$ Uma exceção foi o Brasil, onde os militares, principalmente entre os anos de 1968 e 1973, conseguiram lograr um crescimento econômico significativo e uma maior distribuição de renda, mas que nos anos seguintes mostrou-se incapaz de manter o padrão de crescimento.

\section{Referências:}

COMBLIN, J. A ideologia da segurança nacional: o poder na América Latina. Rio de Janeiro: Civilização Brasileira, 1980.

GRAMSCI, Antonio. Maquiavel, a política e o Estado moderno. 3. ed. Rio de Janeiro: Civilização Brasileira, 1978.

O’DONNELL, G.; SCHMITTTER, P.; WHITEHEAD, L. (orgs.) Transições do regime autoritário: América Latina. São Paulo: Vértice, 1988.

SANTOS, Theotonio dos. América Latina: democratização e ajuste estrutural. Anos 90, Porto Alegre, n. 5, p. 29-44, jul. 1996. 